\title{
Flowability and Strength Properties of High Flowing Self-Compacting Concrete Using for Tunnel Lining
}

\author{
Yun-Wang Choi, ${ }^{1)}$ Wook Choi $^{2)}$ Byoung-Kwon Kim, ${ }^{3)}$ and Jea-Gwone Jung ${ }^{3)}$
}

(Received October 15, 2007, Revised June 17, 2008, Accepted October 30, 2008)

\begin{abstract}
So far, there has been no study of the concrete to strengthen in the lining of the tunnels, except for the study of the stability of subgrade and the tunnel construction technologies. In the existing concrete work for tunnel lining, lots of problems happen due to the partial compaction and the material segregation after casting concrete. Accordingly, the aim of this study is to improve economic efficiency and secure durability through the improvement of the construction performance and quality of the concrete for the tunnel lining among the civil structures. Therefore, the compactability and strength properties of the High Flowing Self-Compacting Lining Concrete (HSLC) are evaluated to develop the mixing proportion for design construction technology of HSLC that can overcome the inner cavity due to the reduced flowability and unfilled packing, which has been reported as the problem in the existing lining concrete. The result of the evaluation shows that the ternary mix meets the regulations better than the binary mix. Consequently, it has been judged applicable to the cement for tunnel lining.
\end{abstract}

Keywords : self-compacting concrete, tunnel lining, flowability

\section{Introduction}

As the demand for tunnel construction increases gradually due to mounting concern about the environmental protection under the geological conditions of Korea, whose over $70 \%$ of the total land area is mountainous, the construction of the highway tunnels including rail transit tunnels has increased rapidly in recent years, together with the development of the high-speed railroad. ${ }^{1}$

The reduction in the number of skilled workers due to the phenomenon of avoidance behaviors of the so-called ' $3 \mathrm{D}$ ' jobs leads to the quality deterioration and the increase of labor cost, which have a bad influence on a tunnel construction. Therefore, a study for technology on the effective tunnel construction has been required to overcome the situation. However, presently, the domestic research practice relating to the tunnel is limited mainly to the tunnel construction works, such as subgrade stability, tunnel excavation method and maintenance technology by means of repair and reinforcement. To point out expressly, the research on the appearance of tunnel and the increase in the quality of material is almost not found because the concrete for the tunnel lining is applied only to the structure that can sustain the structural safety and can bear the lateral pressure from the surroundings.

${ }^{1)}$ KCI Member, Dept. of Civil Engineering, Semyung University Jecheon, 390-711, Korea. E-mail: crete77@semyung.ac.kr

${ }^{2)}$ KCI Member, Dept. of Technical Development, Korea Infrastructure Safety and Technology Corporation, Goyang 411-758, Korea

${ }^{3}$ Dept. of Civil Engineering, Semyung University, Chungbuk 390711, Korea

Copyright (c) 2008, Korea Concrete Institute. All rights reserved, including the making of copies without the written permission of the copyright proprietors.
As for the domestic concrete work for the tunnel lining, various occurrences have been noted, such as the cavitation in the top edge of tunnel due to the material segregation after casting concrete, the incompatibility between supporting materials and subgrade due to the excessive vibration of steel forms, and the local cracking. As one of the methods to solve such problems, plastering work is being applied to the bottom part of the wall of the concrete for tunnel lining with tile or coating, but it isn't the fundamental solution to increase the stability and the durability of the lining concrete. Futhermore, it causes the increase in the maintenance costs. In addition, the economical admixtures, which can be substituted for cement, shall be applied to avoid environmental problems with cement manufacturing.

In case the pulverulent HSLC whose flowability and viscosity are improved is applied to concrete for tunnel lining, it may be possible to reduce the construction period, minimize the vibration of the steel forms, and improve the finishability of the lining wall, which will contribute to the workability. Based on this view, this study have developed the pulverulent HSLC that is mixed with limestone powder and fly ash, and its rheological properties and robustness properties of hardened concrete are analyzed and reviewed.

\section{Summary of test}

\subsection{Test material}

\subsubsection{Cement and admixture}

The ordinary portland cement (OPC) with density of $3,150 \mathrm{~kg} / \mathrm{m}^{3}$ and fineness of $0.3540 \mathrm{~m}^{2} / \mathrm{g}$ has been used, and the admixture of limestone powder (LSP) and fly ash density (FA) has been used to 
enhance the rheological properties upon mixing with HSLC. Its chemical composition and physical properties are shown in Table 1.

\subsubsection{Aggregate}

River sand from Nakdonggang river (S) has been used for the fine aggregate, and the crushed aggregate $(\mathrm{G})$ of max. $20 \mathrm{~mm}$ has been used for the coarse aggregate. The physical properties of the fine and coarse aggregate are shown in Table 2.

\subsubsection{Admixture}

Polycarboxylate superplasticizer (SP) with solid content of 35\% produced by a domestic $\mathrm{H}$ company has been used for securing the high flowability and adjusting the air content. and air entrainer (AE) has been used for adjusting the air content.

\subsection{Test of rheological properties for each admixture}

Because the flowability and viscosity vary significantly according to the properties of admixture used to manufacture the pulverulent HSLC, it is essential to measure the rheology of pulverulent mixtures on a quantitive level. Accordingly, the paste has been manufactured according to the type of admixture and mixing rates on OPC and the test of rheological properties relating to plastic viscosity, entrapped water ratio, and the type of SP has been conducted.

\subsubsection{Plastic viscosity}

The paste mixed with each pulverulent mixture has been manufactured. The changes of shear stress have been measured according to the various shear rates, using Brookfield Viscometer (Model LVDV II+) which adopted the cylinder-typed spindle (Fig 3). In addition, in order to avoid the hysteresis of the test value on the hysteresis loop area, the shear stress has been measured using the gradient-descent method with the shear rate of 100, 80, 60, 50, $30,20,12$, and 5rpm. The shear stress has been calculated with the modulus that is applied taking into consideration the contact side between samples and spindles, and it has been interpreted on Bingham equation through the linear regression. ${ }^{2,3}$

Fig. 1 shows Bingham model and Entrapped water ratio.

As for the OPC volume, the mixed pastes have been manufactured mixing two kinds of admixtures (LSP and FA), setting LSP at four levels $(0,15,30$ and 45\%) and FA at four levels $(0,10,20$ and $30 \%$ ). The mix of the paste is shown in Table 3 .

\subsubsection{Entrapped water ratio and deformation coefficient}

As for OPC, the cement paste is manufactured, setting volume ratio of LSP at four levels $(0,15,30$ and $45 \%)$, and volume ration of FA at four levels $(0,10,20$ and $30 \%)$, and changing water/ powder $(\mathrm{Vw} / \mathrm{Vp})$ volume ratio at four levels respectively $(1.1,1.2$, 1.3 and 1.4). The deformation coefficient is calculated by obtaining the relative flow area ratio. The relative flow area ratio is calculated by means of the following numerical expression using the average
Table 2 Physical properties of aggregates.

\begin{tabular}{c|c|c|c|c|c}
\hline Types & $\begin{array}{c}\text { Gmax } \\
(\mathrm{mm})\end{array}$ & $\begin{array}{c}\text { Density } \\
\left(\mathrm{kg} / \mathrm{m}^{3}\right)\end{array}$ & $\begin{array}{c}\text { Absorption } \\
(\%)\end{array}$ & F.M. & $\begin{array}{c}\text { Bulk density } \\
\left(\mathrm{kg} / \mathrm{m}^{3}\right)\end{array}$ \\
\hline \hline $\mathrm{G}$ & 20 & 2,710 & 1.01 & 7.96 & 1,611 \\
\hline $\mathrm{S}$ & - & 2,550 & 2.07 & 2.89 & 1,637 \\
\hline
\end{tabular}

Table 3 Mixture proportions of cement paste.

\begin{tabular}{|c|c|c|c|c|}
\hline $\mathrm{W}(\mathrm{g})$ & $\mathrm{OPC}(\mathrm{g})$ & \multicolumn{3}{|c|}{ Admixture Mineral (g) } \\
\hline \multirow{7}{*}{75} & 150.0 & \multicolumn{3}{|c|}{ "0\% } \\
\hline & 127.5 & \multirow{3}{*}{ LSP } & $15 \%$ & 19.2 \\
\hline & 105.0 & & $30 \%$ & 38.4 \\
\hline & 82.5 & & $45 \%$ & 19.2 \\
\hline & 135.0 & \multirow{3}{*}{ FA } & $10 \%$ & 10.4 \\
\hline & 120.0 & & $20 \%$ & 20.8 \\
\hline & 105.0 & & $30 \%$ & 31.1 \\
\hline
\end{tabular}
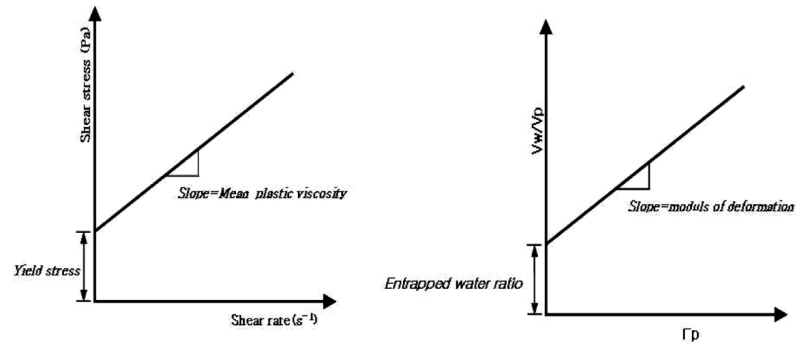

Fig. 1 Bingham model \& entrapped water ratio.

flow value obtained from the two successive flow tests. ${ }^{4}$

$$
\Gamma p=\frac{\pi\left(F_{P} / 2\right)^{2}-\pi\left(F_{o} / 2\right)^{2}}{\pi\left(F_{o} / 2\right)^{2}}=\left(F_{P} / F_{o}\right)^{2}-1
$$

wher, $F_{P}=$ Flow value of paste $(\mathrm{mm})$

$F_{o}=$ Sectional diameter of flow-cone $(100 \mathrm{~mm})$

\subsubsection{Flow property by high-range water reducer (super-} plasticizers)

In order to enhance the flowability of pulverulent HSLC, the paste whose amount is fixed to $35 \%$ is manufactured as for the pulverulent bodies respectively to examine the flow property of pulverulent by the ratios of the addition of admixture SP, and the flow value is determined according to the rations of the addition of admixture SP.

\subsection{Concrete test}

The standard mix to meet the HSLC performance evaluation is set as shown in Table 4, just like as that of Japan Society of Civil Engineers for the second grade performance standards of "the test

Table 1 Chemical components and physical properties of OPC, LSP and FA.

\begin{tabular}{c|c|c|c|c|c|c|c|c|c|c|c}
\hline Items & $\begin{array}{c}\mathrm{SiO}_{2} \\
\text { Types }\end{array}$ & $\begin{array}{c}\mathrm{Al}_{2} \mathrm{O}_{3} \\
(\%)\end{array}$ & $\begin{array}{c}\mathrm{Fe}_{2} \mathrm{O}_{3} \\
(\%)\end{array}$ & $\begin{array}{c}\mathrm{CaO} \\
(\%)\end{array}$ & $\begin{array}{c}\mathrm{Na}_{2} \mathrm{O} \\
(\%)\end{array}$ & $\begin{array}{c}\mathrm{K}_{2} \mathrm{O} \\
(\%)\end{array}$ & $\begin{array}{c}\mathrm{MgO} \\
(\%)\end{array}$ & $\begin{array}{c}\mathrm{SO}_{3} \\
(\%)\end{array}$ & L.O.I & $\begin{array}{c}\text { Density } \\
\left(\mathrm{kg} / \mathrm{m}^{3}\right)\end{array}$ & $\begin{array}{c}\text { Specific surface area } \\
\left(\mathrm{m}^{2} / \mathrm{g}\right)\end{array}$ \\
\hline \hline OPC & 21.60 & 6.00 & 3.10 & 61.40 & - & - & 3.40 & 2.50 & 0.03 & 3,150 & 3,540 \\
\hline LSP & 11.06 & 4.13 & 1.44 & 43.80 & 0.18 & 1.02 & 1.42 & 0.30 & 35.66 & 2,690 & 4,170 \\
\hline F A & 58.20 & 26.28 & 7.43 & 6.51 & 0.80 & - & 1.10 & 0.30 & 3.20 & 2,180 & 3,550 \\
\hline
\end{tabular}


Table 4 Specification of HSLC proposed by JSCE.

\begin{tabular}{l|c|c|c|c}
\hline \multicolumn{2}{r|}{ Rank } & 1 & 2 & 3 \\
\hline \hline \multirow{2}{*}{$\begin{array}{c}\text { Items } \\
\text { construction } \\
\text { condition }\end{array}$} & $\begin{array}{c}\text { Minimum gap between } \\
\text { reinforcement (mm) }\end{array}$ & $35 \sim 60$ & $60 \sim 200$ & $\geq 200$ \\
\cline { 2 - 5 } & $\begin{array}{c}\text { Amount of } \\
\text { reinforcement }\left(\mathrm{kg} / \mathrm{m}^{3}\right)\end{array}$ & $\geq 350$ & $100 \sim 350$ & $\leq 100$ \\
\hline Flow ability & Slump flow (mm) & $600 \sim 700$ & $600 \sim 700$ & $500 \sim 650$ \\
\hline $\begin{array}{c}\text { Segregation } \\
\text { resistance } \\
\text { ability }\end{array}$ & $\begin{array}{c}\text { Time required to flow } \\
\text { through V-funnel (s) }\end{array}$ & $9 \sim 20$ & $7 \sim 13$ & $4 \sim 11$ \\
\cline { 2 - 5 } & $\begin{array}{c}\text { Time required to reach } \\
500 \text { mm of slump flow (s) }\end{array}$ & $5 \sim 20$ & $3 \sim 15$ & $3 \sim 15$ \\
\hline \multicolumn{2}{c}{ Filling height of U-box test (mm) } & $\geq 300$ & $\geq 300$ & $\geq 300$ \\
\hline
\end{tabular}

method on the self-compacting concrete type5)." For setting the mix to meet such standards, a trial mix is conducted.

In the test, the mix of HSLC has been conducted on the modified and complemented mix design of Nan-Su, using PF value obtained by applying together the weighted values based on the ratio of fine aggregates on the ratio of mass per unit volume in the dense state rather than the loose state. ${ }^{6,7}$ The standard mix proportion of HSLC has been set at $1.12 \%$ of the aggregate filling ratio (PF), $48 \%$ of the fine aggregate ratio, and $0.38 \%$ of water/powder ratio. LSP mixing rates vary as set at the volume ratio of four levels $(0$, 15,30 and $45 \%$ ) to OPC. The mixing work is conducted at the volume ratio of four levels $(0,10,20$ and $30 \%)$ to OPC for improving the rheological performance such as flowability and compactability of HSLC. In order to evaluate the self-compactability of the fresh HSLC, the tests are conducted for Slump-flow, V-funnel flow time, Slump-flow time up to $500 \mathrm{~mm}$, and U-box filling height. The compressive strength of the hardened concrete has been determined by making cylindrical specimens of $\Phi 100 \times 200 \mathrm{~mm}$.

\subsubsection{Test for setting}

The various setting time of the fresh concrete is determined by the time taken to the setting value of the initial setting and the final setting in accordance with KS L 2436.

\subsubsection{Test of flowability and loss of flowability}

The slump-cone test has been used for the HSLC flowability test: the slump cone was completely filled with sample without compaction, the cone was lifted and the largest diameter of resulting circular spread was measured. And the second diameter of the spread at an approximate perpendicular angle to the original measured diameter was also measured. The average of two values was calculated as a slump flow value. The loss of flowability has been measured at 30,60 and 90 minutes after the measurement of the initial slump-cone.

\subsubsection{Test for resistance of material segregation}

As for the resistance of the material segregation of HSLC, in this test, slump-flow time(sec) up to $500 \mathrm{~mm}$ and the V-funnel flow time have been measured.

\subsubsection{Test of compactability}

As for the HSLC compactability test, the filling height that the flowing sample concrete reached through the reinforcing bars has been measured, after the partition in the middle is lifted up from the U-typed box where the sample concrete is filled.

\subsubsection{Test of mechanical property}

As for the evaluation of the mechanical property on the concrete compressive strength, a test specimen has been made up in the cylindrical mold of $\varnothing 100 \times 200 \mathrm{~mm}$ without compaction, and the mold has been taken off for ponding curing in the water reservoir of $23 \pm 2^{\circ} \mathrm{C}$ for the curing. The compressive strength test has been conducted at the third, seventh, and twenty-eighth date in the material age in accordance with KS F 2405.

\section{Test result and review}

\subsection{Property of paste}

\subsubsection{Plastic viscosity}

In Figs. 2 and 3, the plastic viscosity of the mixed paste of OPC with LSP and FA has been arranged.

As for LSP, the higher viscosity than that of the standard has been checked in the mix of 15,30 and $45 \%$, and the more, in the mix of $45 \%$, the viscosity is $30 \%$ higher than that of the standard. As for FA, the lower viscosity than that of the standard has been checked in the mix of 10,20 and $30 \%$, and in the mix of $30 \%$, the

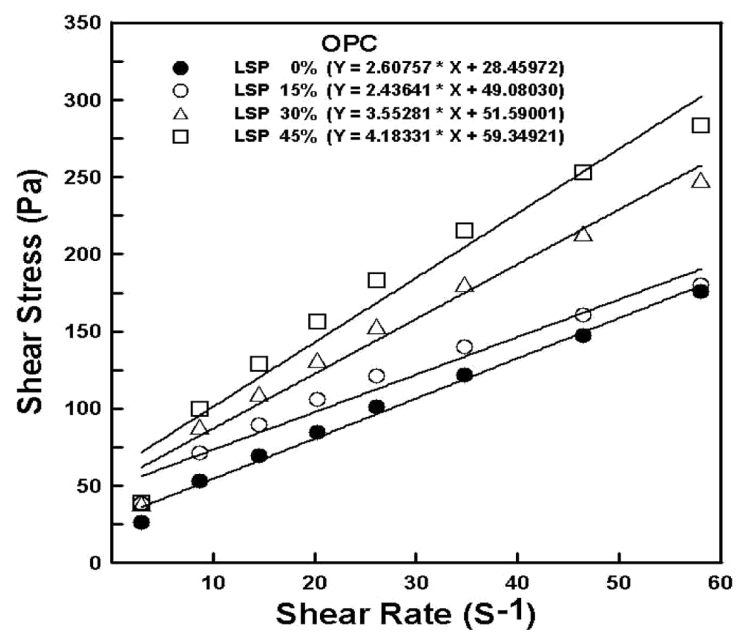

Fig. 2 Plastic viscosity of paste mixing admixture (LSP).

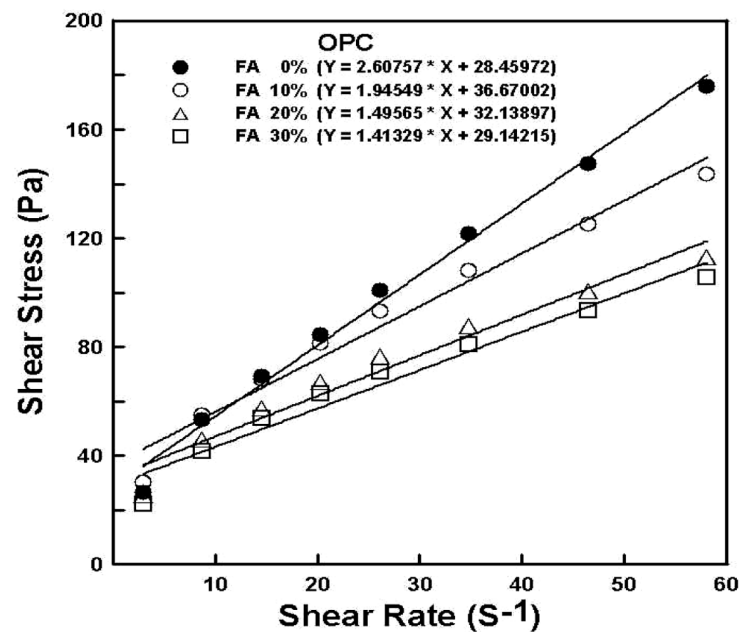

Fig. 3 Plastic viscosity of paste mixing admixture (FA). 
viscosity is $36 \%$ lower than that of the standard. From this result, it has been found out that the viscosity of OPC is increased in the admixture of LSP, while decreased in the admixture of FA, in case of the intrinsic plastic viscosity of the pulverelent body without mixing high range water reducer. The viscosity is the vital factor in mixing HSLC. Therefore, it is essential to adjust the mixing rate to secure the most suitable viscosity when LSP and FA are used for the admixture for HSLC, because the material segregation and aggregate interlock leads to closing the pores between coarse aggregate and mortar, due to the possible drop in compactability and filling rate from the pore closing.

\subsubsection{Evaluation of entrapped water ratio and deformation} coefficient

In Figs. 4 and 5, the entrapped water ratio and the deformation coefficient of the mixed paste of OPC with LSP and FA are arranded. After applying the linear regression to $\mathrm{Vw} / \mathrm{Vp}$ and the relative flow area rate(p), the $y$ section value indicates the restraint when the flow area ratio is $0, r$ and the gradient of the straight line indicates the deformation coefficient.

In general, the larger number of the entrapped water ratio demands more unit water required to increase the same flow because the combined water of the paste is not effectively worked for the flowability, and is restrained much to the binders. It means that dropping flowability is occurred in the same amount of combined water. In the mean time, the larger number of the deformation coefficient demands a lot of the necessary $\mathrm{Vw} / \mathrm{Vp}$ in the same flow area ratio (in case of the same deformation), because the combined water is required much for deforming in the same amount of pulverulent body. It has been reported that the increased demand of combined water is related to the increased plastic viscosity. The result of Fig. 4 shows the measurement of combined water rates as $1.1689,1.1866$ and 1.2016 to the LSP mixing rates of 15,30 and $45 \%$ respectively, together with the deformation coefficient of $0.0607,0.0617$ and 0.0646 . It means that the increased mixing rate of LSP leads to the increased entrapped water ratio and deformation coefficient. The result of Fig. 5 shows the measurement of the combined water rates as $1.1501,1.1411$ and 1.1214 to the FA mixing rates of 10,20 and $30 \%$ respectively, together with the

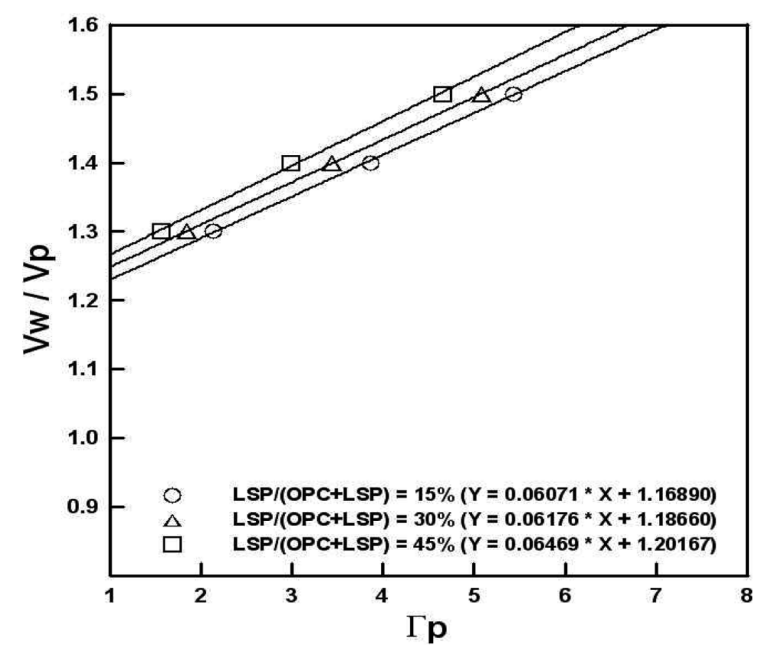

Fig. 4 Restraint and deformation coefficient of paste mixing admixture (LSP).

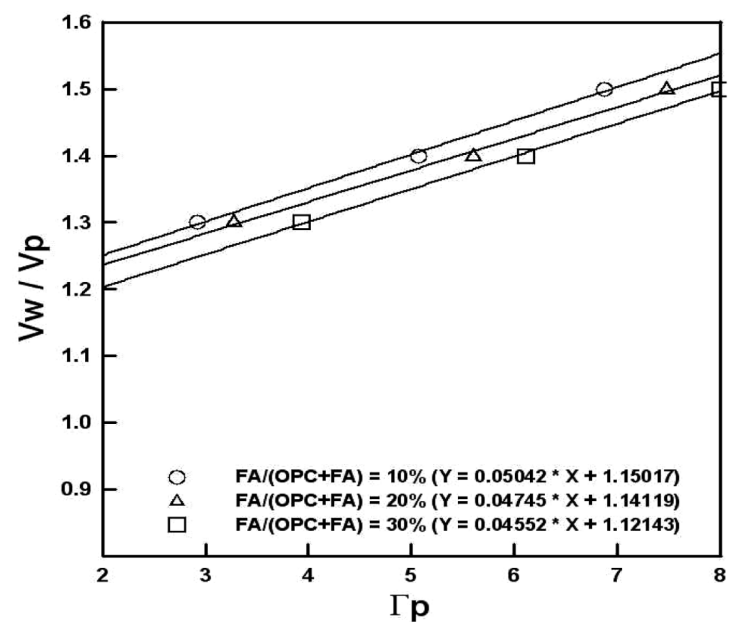

Fig. 5 Restraint and deformation of paste mixing admixture (FA).

deformation coefficient of $0.0834,0.0504,0.0474$ and 0.0455 . It means that the increased mixing rate of FA leads to the decreased entrapped water ratio and deformation coefficient. From these results, it is determined that LSP is applicable admixture to decrease flowability and increase viscosity, while FA is applicable admixture to increase the flowability and decrease the viscosity. Accordingly, for securing the adequate flowability and viscosity required to HSLC, it is required to apply the Composition Class 3 of the HSLC mix together with the admixtures of LSP and FA

\subsubsection{Evaluation of flow by the ratio of the addition of high range water reduce}

In Fig. 6, the flow values of the paste by changing the rates of addition of SP have been arranged to determine the sensitivity of the pulverulent body over the polycarboxylate superplasticizer (SP). The result of Fig. 6 shows the more increased amount of $\mathrm{SP}(\mathrm{P} * \%)$, the more increased flow of the paste in case of the pulverulent applied to HSLC. It indicates the required amounts of SP are $0.5 \%, 1.4$ and $9 \%$ over LSP, OPC and FA in case the flow value is $250 \mathrm{~mm}$. Accordingly, it has been judged that the sensitivity of FA is remarkably decreased, while that of LSP is a little increased in its sensitivity over SP, than that of OPC. From these results, it is

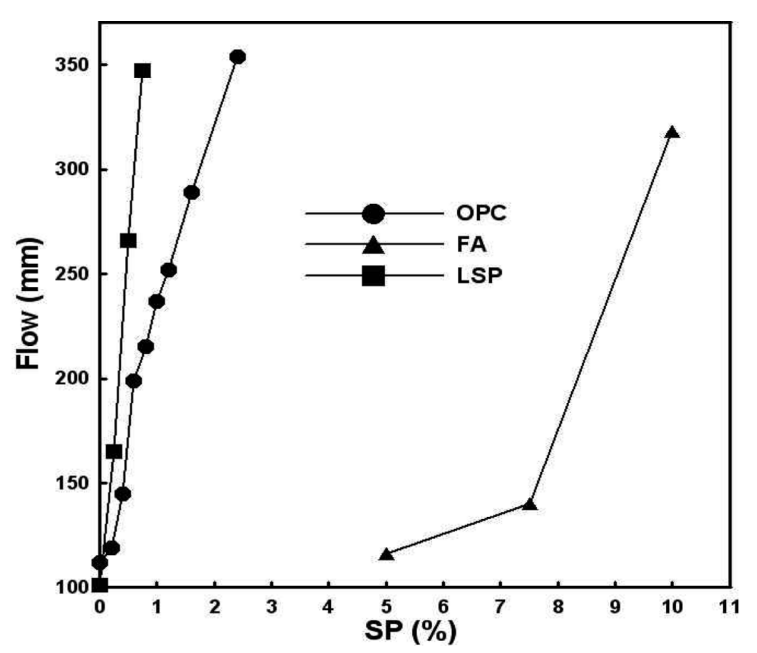

Fig. 6 Flow value by pulverulent body by adding ratio of SP admixture. 
desirable that in case SP admixture is not added to HSLC, LSP is adequate admixture to decrease the flowability and increase the viscosity and FA is adequate admixture to increase the flowability and decrease the viscosity, while in case polycarboxylate superplasticizer SP is added to HSLC, LSP is adequate admixture to increase the flowability, and FA is adequate admixture to increase the viscosity The result conflicting with each other is understood that the sensitivity of SP admixture works better than the proper rheological property of the pulverulent body in LSP and FA.

\subsection{Evaluation of flowability of HSLC}

\subsubsection{Setting property}

Fig. 7 shows the value of concrete penetration resistance based on the time elapsed for the HSLC, in which LSP over OPC was changed to four levels $(0,15,30$ and $45 \%)$. From the result of Fig. 7, it has been observed that the initial and final settings are delayed according to the increase of the mixing rate and that the initial setting is delayed about $5.1 \%$, the final setting $6.2 \%$ according to the increase of LSP mixing rate by $15 \%$. The remarkable delay checked in the maximum $45 \%$ of LSP mixing is about $21.5 \%$ for the initial setting and about $45 \%$ for the final setting. Fig. 8 and 9 shows the value of concrete penetration resistance based on the time elapsed for the HSLC of Composition Class 3 which is mixed simultaneously with LSP and FA over OPC. From the result of Fig. 8, it has been observed that the initial and the final settings are delayed according to the increasing mixing rate of FA over $15 \%$ of LSP and in case of mixing FA, according to the increase of FA mixing rate by $10 \%$, the initial setting is increased by $5.7 \%$, while the final setting is delayed by about $3.7 \%$, from that of the standard value. In case of Fig. 9, the initial and the final settings are delayed according to the increased mixing rate of FA over $30 \%$ of LSP, and in case of mixing FA, according to the increase of FA mixing rate by $10 \%$, the initial setting is increased by about $3.7 \%$, while the final setting is delayed about $2.9 \%$, from that of the standard value. The reason of these phenomena can be assumed that the initial setting is delayed by the admixture property that LSP is non-reactive particle, and FA is a reactive pozzolan particle, whose reaction is to be checked in the long period of time.

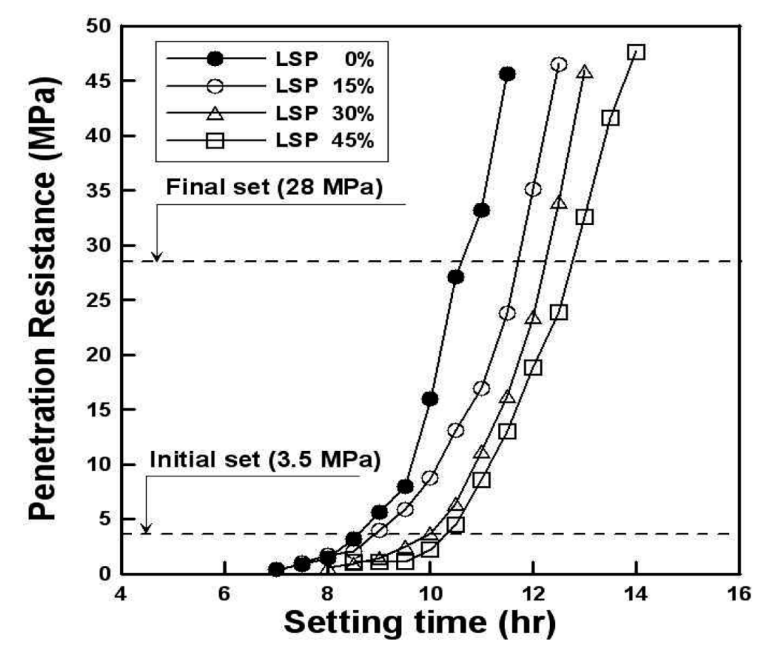

Fig. 7 Setting property by composition class 2 (LSP).

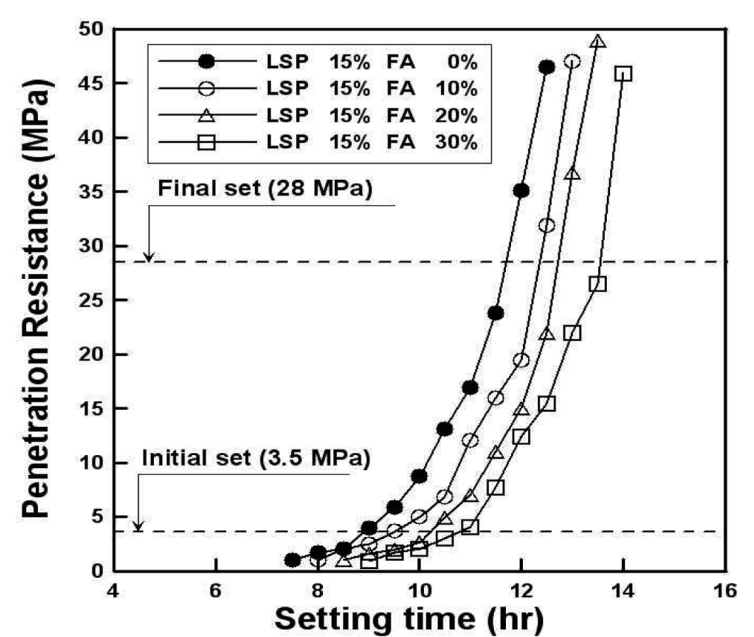

Fig. 8 Setting property by composition class 3 (LSP15-FA).

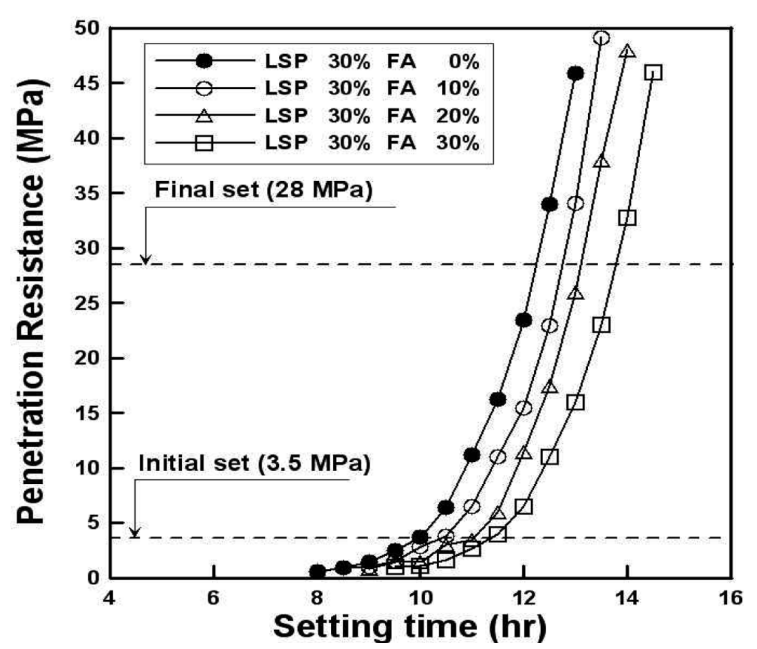

Fig. 9 Setting property by composition class 3 (LSP30-FA).

\subsubsection{Properties of flowability and loss of flowability}

In Fig. 10, the result of the measurements of the flowability of the fresh HSLC, which is mixed with LSP and FA, have been arranged. From the result of Fig. 10, it has been observed that as

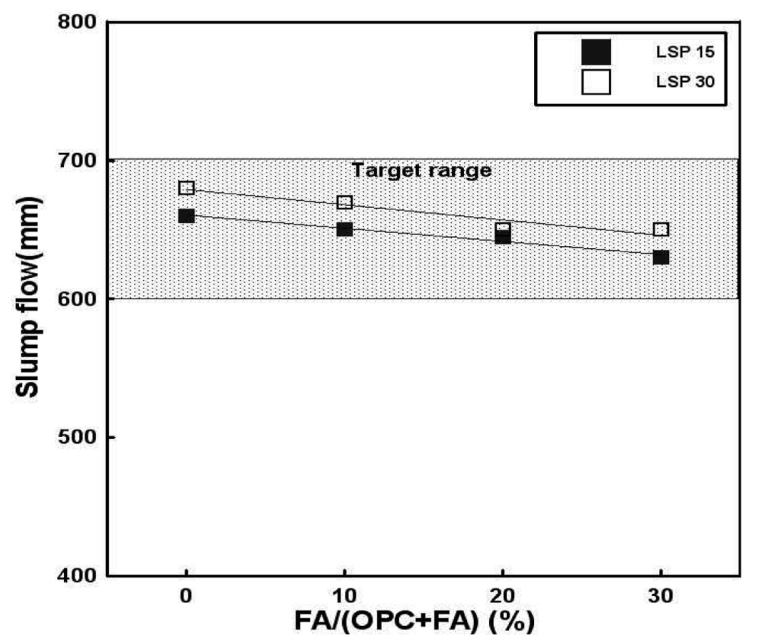

Fig. 10 Slump-flow by the mixing rate of composition class 3 . 
the mixing rate of LSP is increased, the slump-flow is increased, while the mixing rate of FA is increased, the slump-flow is deceased. In case of a mix of HSLC (Composition Class 3) with LSP and FA, the slump-flow of $600 \sim 700 \mathrm{~mm}$ meets the standards of the performance goal over the $\sim$ all mixing rates. From this result, it is desirable to mix LSP for enhancing the flowability of HSLC. The flowability of the slulmp-flow has been evaluated to check the slump-flow loss rate on the flowability loss of HSLC, by measuring it at from $10,30,60$, and up to 90 minutes after input the mixing water for HSLC mixing. Fig. 11 shows the slump-flow loss ratio based on the time elapsed for the HSLC, in which LSP over OPC was changed to four levels $(0,15,30$ and $45 \%$ ). In case of HSLC (Composition Class 2) mixed with LSP, the slump-flow loss ratio is inclined to decrease according to the increase of the mixing ratio of LSP. Though the results of less than $600 \mathrm{~mm}$ of standard values have been checked at the all mixing stages before the elapsed time of 60 minutes, in the higher mixing rate of LSP $45 \%$, the higher flowability than that of the standard mixing is maintained even after the elapsed time. As the mixing rate is increased, the effect has been judged to be active for a longer period of time because the SP admixture gets the higher sensibility according to the increased rate of mixing LSP. Fig. 12 and 13 show the slump-flow loss rate based on the time elapsed for the HSLC (Composition Class 3) that is mixed simultaneously with LSP and FA over OPC. From the results of Fig. 12 and 13, the slump-flow loss rate is decreased according to the lapse time in the all mixing pattern, while the slump-flow loss rate of HSCL is decreased in LSP $30 \%$ than in LSP $15 \%$. Consequently, HSLC mix with adequate LSP has been judged to be applicable considering the time elapsed before pouring the lining concrete at the site of the tunnel construction.

\subsubsection{Resistance property of material segregation}

In Fig. 14, the resistance of the material segregation of the HSLC (Composition Class 3), which is mixed with admixture, has been arranged. The reaching time to the slump-flow $500 \mathrm{~mm}$ of the standard HSLC only mixed with OPC is 6.35 seconds and the flow time of V-funnel is 7.53 seconds. The reaching time 6 of HSLC slump-flow $500 \mathrm{~mm}$ meets the standard performance for the resistance of the material segregation at the all mixing patterns. However, as for the flow time of the V-funnel, the flow time is

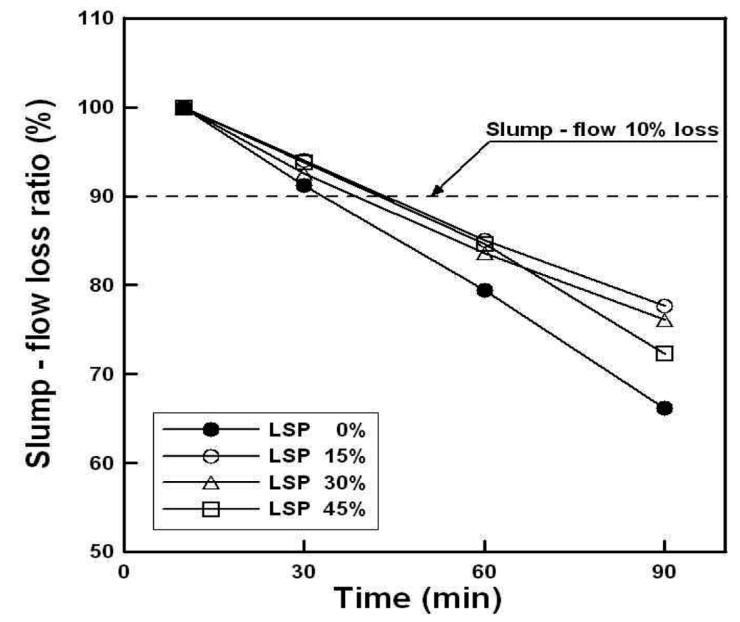

Fig. 11 Slump-flow loss by composition class 2 (LSP) mixing rate.

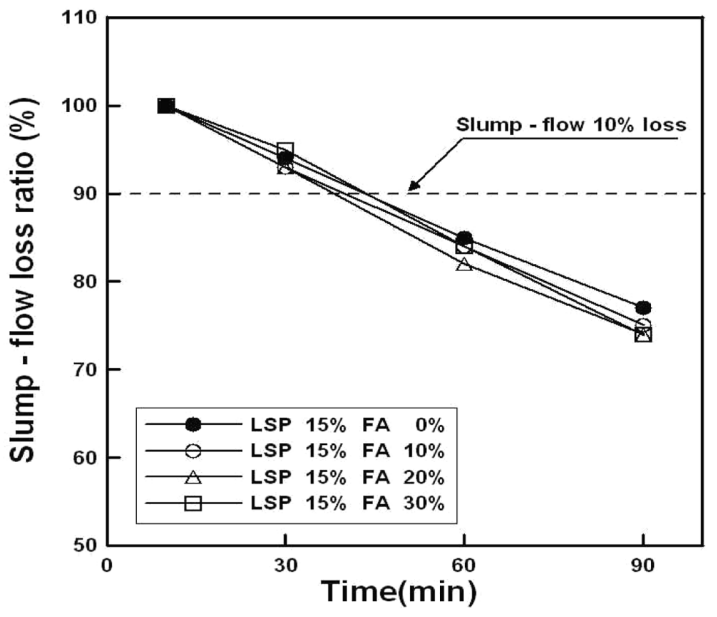

Fig. 12 Slump-flow loss by composition class 3 (LSP15-FA) mixing rate.

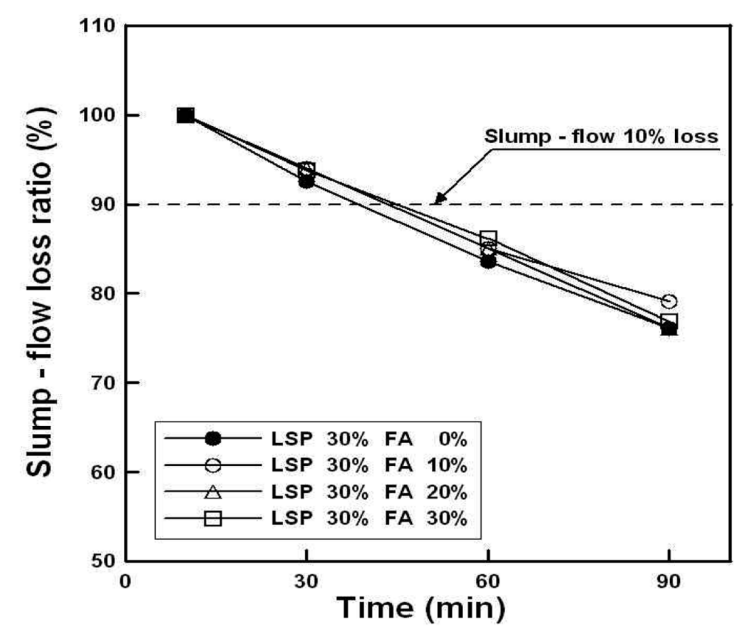

Fig. 13 Slump-flow loss by composition class 3 (LSP30-FA) mixing rate.

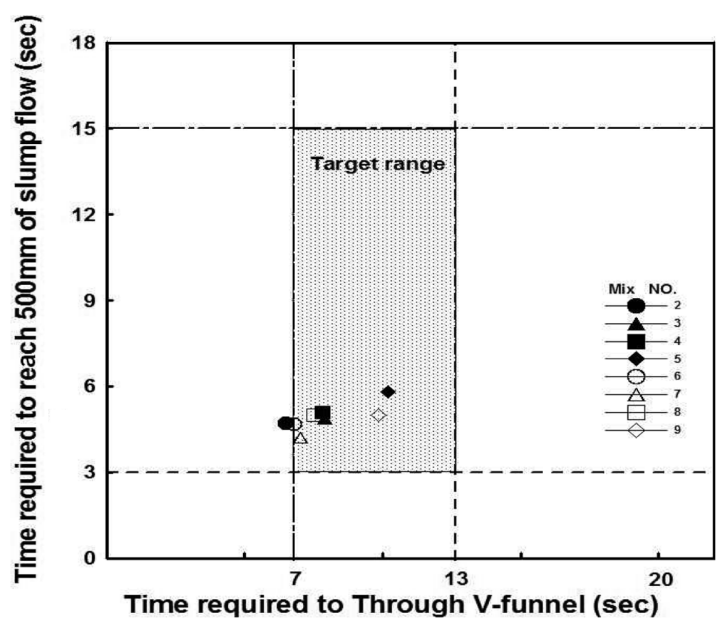

Fig. 14 Slump-flow loss by composition class 3 (LSP30-FA) mixing rate.

indicated seven seconds and rather less than that in the HSLC of Composition Class 2 (LSP 15\% and 30\%), and meets the JSCE second grade in the standards for the resistance of the material segregation as the all mixing stages. As a result, FA has been 
judged to be necessary due to the difficulty to secure the HSLC viscosity by mixing LSP alone.

\subsubsection{Filling property}

In Fig. 15, the filling and the space passing percentage of the HSLC (Composition Class 3), which is mixed with admixture, have been arranged. Fig. 15 shows that the filling height of the Ubox for the standard HSLC using OPC only is $350 \mathrm{~mm}$. In case of HSLC, according to the increased mixing rate of FA, the filling height of the U-box has been decreased, and the filling performance is rather high in the HSLC mixed with $15 \%$ of LSP than that of $30 \%$ of LSP. The HSLC mixed with FA of $30 \%$ or more has been judged to decrease the filling performance.

\subsection{Evaluation of the Compressive strength property of HSLC}

In Fig. 16, the compressive strengths for each material age of HSLC, which is mixed with LSP and FA, have been arranged. As shown in Fig. 16, the compressive strength in the material age of 28 days for the standard HSCL used OPC only is indicated as $42 \mathrm{MPa}$, and the compressive strengths in the material age of 28 days for HSCL mixed with LSP of 0,15 and 30\% are decreased

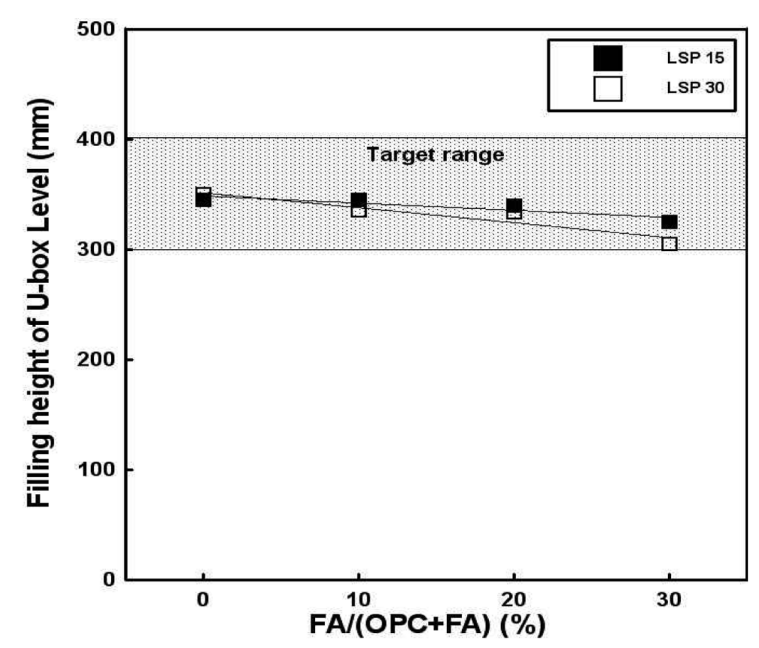

Fig. 15 Filling height of U-box.

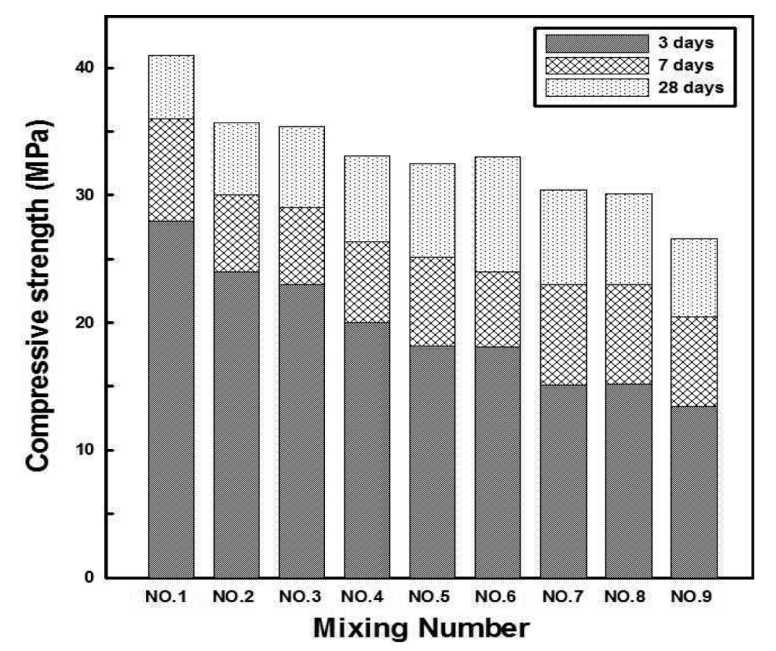

Fig. 16 Compressive strength of HSLC by material age. by about $12 \%$ according to the increased LSP by $15 \%$. the compressive strength of the material age is decreased according to the replacement rate of FA.

In case of HSLC with LSP 30\% and FA 30\% (NO.9), the strength property is less safe than the target strength of $28 \mathrm{MPa}$. of this study. From the result so far, it has been judged that the adequate HSLC mix for the required strength for the lining concrete is the HSLC (Composition Class 3) of $30 \mathrm{MPa}$ or more with LSP 30\% and FA 20\%. Fig. 17 shows the compressive strength according to the LSP mixing rates. The strength of the pulverulent HSLC is depended upon the mixing rates of LSP, and the compressive strength of material age of 28 day by the mixing rate of LSP can be estimated on the following expression. Accordingly, it is determined that the adequate mixing rate of LSP is $34 \%$, at the least required mixing strength of $30 \mathrm{MPa}$ with considering $24 \mathrm{MPa}$ of the concrete design strength for the tunnel lining.

$$
Y=-0.318 X+41.08
$$

Where, Y : Compressive strength of 28 days according to the LSP mixing rate $(\mathrm{MPa})$

$$
\mathrm{X} \text { : Mixing rate of LSP (\%) }
$$

From the above result, it has been judged that the adequate regulation of the HSLC strength shall be set by the mixing rate of LSP rather than the existing water-cement ratio.

\section{Conclusions}

1) In case the proper viscosity of pulverulent body is compared with that of cement, the lime powder increases the viscosity of cement, and on the contrary, the fly ash admixture decreases the viscosity of OPC. As the mixing rate of the lime powder is increased, the entrapped water ratio and the deformation coefficient are increased, while the mixing rate of the fly ash is increased, the entrapped water ratio and the deformation coefficient is decreased.

2) Compared with cement, the lime powder gets rather high sensibility against SP, while the sensibility of the fly ash is considerably decreased. The reason of the decreased sensibility of the fly ash is deemed that SP is absorbed by the incombustible

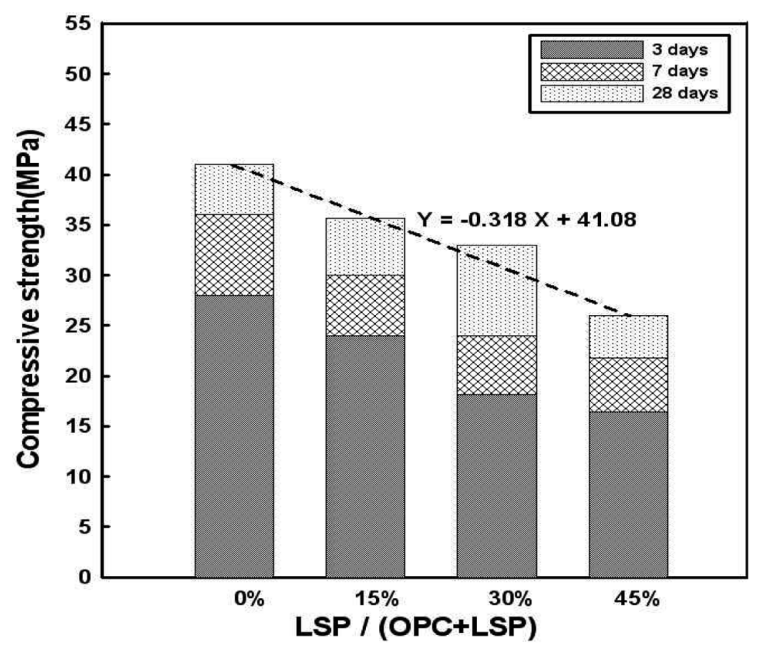

Fig. 17 Compressive strength of HSLC by LSP mixing rate. 
carbon particle contained in the fly ash.

3) As the mixing rate of the lime powder in the self-compacting concrete (Composition Class 2) is increased, the initial and the final setting are delayed accordingly, and likewise, that of the mixing rate of the fly ash in the self-compacting concrete (Composition Class 3) is delayed accordingly.

4) As the mixing rate of the lime powder is increased, the slump-flow is increased, while the slump-flow is decreased at the mixing rate of the fly ash is increased. In case of $30 \%$ of the lime powder in the self-compacting concrete (Composition Class 3) and $30 \%$ (NO.9) of the fly ash, the filling performance is decreased due to the excessive mixing viscosity of the fly ash.

5) The strength of 30\% lime powder and the fly ash $30 \%$ (NO.9) in the self-compacting cement is not met to the target strength of $30 \mathrm{MPa}$. After analyzing the compressive strength of lime of 28 days, it is determined that the adequate mixing rate of the required lime powder is $34 \%$.

From these results, when the lime powder and the fly ash are applied to the self-compacting cement where the Polycarboxylate superplasticizer is used, it is required to mix the self-compacting cement (Composition Class 3) for securing the adequate viscosity. The adequate mixing rate of the lime powder has been judged to be about $41 \%$ for the lime powder in the self-compacting concrete for the tunnel lining and for the regular strength.

\section{Acknowledgements}

This research was supported by a grant from Korea Institute of Construction and Transportation Technology Evaluation (05 CCT
D11-1). The financial support is gratefully acknowledged.

\section{References}

1. Choi, Yun-Wang, Kim, Yong-Jik, and Jung, Jea-Gwone, "Flow Property of Self-Compacting Cement for Tunnel Lning," KSCE Colllection of papers, Vol. A, 2006, 331 pp.

2. Yoon, Jae-Hwan, "Research on the Rheology Property on Superplasticizing Cocrete," KIET Colllection of Papers, Vol. 12, 1997, pp. 67 76.

3. 吳相均, “高流動ユソクリ一トのレオロヅ一評價および流 動設計,”東京大學, 1999.

4. Choi, Yun-Wang, Kim, Yong-Jik, Choi, Wook, "Quality Property of Self-Compacting Concrete Mixed with Tailing of Sangdong Mine," KCN Collection of Papers, Vol. 18-6, Dec. 2006, pp. 777 783.

5. Domone, P. L., "Self-Compacting Concrete: An Analysis of 11 Years of Case Studies," Cement and Concrete Composite, Vol. 28, Issue 11, 2006, pp. 197 208.

6. Choi, Yun-Wang, Kim, Yong-Jic, Shin, Hwa-Cheol, Moon, Han-Young, "An Experimental Research on the Fluidity and Mechanical Properties of High-Strength Lightweight Self-Compacting Concrete," Cement and Concrete Research, Vol. 36, Issue 9, 2006, pp. 1595 1602.

7. Choi, Yun-Wang, Jung, Moon-Yeong, Moon, Dae-Jung, Ahn, Seong-Il, "The Optimum Mixing of Self-Compacting Concrete in Light with Aggregate Filling Rate and Volume Ratio of Fine Aggregate," KCN Automn Collection of Papers, KCN, Vol. 14-2, 2002, pp. 549 554. 